\title{
Tradução coletiva e criativa do Entremés de la Ropavejera, de Quevedo y Villegas
}

\section{Collective and creative translation of Quevedo y Villegas' Entremés de la Ropavejera}

\author{
Andrea Cesco* \\ Beatrice Távora**
}

* Professora Associada da Universidade Federal de Santa Catarina (PGET/UFSC/CNPq).

E-mail: andrea.cesco@gmail.com

** Doutoranda Programa de Pós-Graduação em Estudos da Tradução da Universidade Federal de Santa Catarina, bolsista Capes (PGET/UFSC/Capes). E-mail: tavorabeatrice@gmail.com

TradTerm, São Paulo, v.38, fevereiro/2021, p. 61-80 
Resumo: A tradução coletiva é apontada por Haroldo de Campos (2010) como um dos caminhos possíveis para textos possuidores de alta complexidade e que, em princípio, seriam intraduzíveis. 0 trabalho de cooperação, através de uma equipe orientada para um alvo comum seria, segundo o autor, uma possibilidade de abordagem que poderia fomentar traduções criativas, voltadas para a manutenção do signo estético em detrimento de uma fidelidade ao significado textual. A partir destes postulados, este artigo se propõe a socializar a experiência de tradução coletiva do Entremés de la Ropavejera (1670), de Francisco de Quevedo y Villegas (1580-1645), realizada pelo Núcleo Quevedo de Estudos Literários e Traduções do Século de Ouro, da UFSC, enfatizando reflexões e escolhas envolvidas nesse processo. A história do entremez gira em torno da personagem ropavejera (remendeira), que atende na sua loja os clientes que chegam em busca de pomadas, postiços e 'peças de reposição' para remendar ou reparar em seus corpos o dano causado pela idade. As discussões acerca do processo tradutório do texto permitiram a elaboração de uma metodologia de trabalho que envolveu a utilização de vários recursos, como o acesso a dicionários especializados e de época, a consulta à crítica literária e à pesquisa histórica para a aproximação ao contexto de produção, que aqui são apresentados e discutidos. Pretende-se, desta forma, contribuir com a divulgação dos estudos sobre o Século de Ouro no cenário nacional.

Palavras-chave: Tradução coletiva; Tradução criativa; Entremés de la Ropavejera; Quevedo y Villegas.

Abstract: Haroldo de Campos (2010) sees the process of collective translation as one of the possible solutions for high-complexity texts that would be, in principle, untranslatable. He believes cooperative work among the members of a team oriented towards a common goal would be a possible approach that could foster creative translations, aimed at maintaining the aesthetic sign at the expense of fidelity to textual meaning. Based on these postulates, this paper reports the collective translation experience of Entremés de la Ropavejera (1670), by Francisco de Quevedo y Villegas (1580-1645), undertaken by the Núcleo Quevedo de Estudos Literários e Traduções do Século de Ouro [Quevedo Siglo de Oro Studies and Translation Research Group] (UFSC, Brazil), with a focus on reflections and choices involved in this process. This entremez revolves around the character ropavejera [patcher], who serves customers that come to her shop in search of ointments, removable and 'spare' parts to mend or repair the damage caused by old age. Discussions about the text's translation process allowed the development of a work methodology that involved the use of various resources, such as access to specialized periodic dictionaries and literary criticism, and historical research to approach the context of production, which are presented and discussed here. It also intends to contribute to the dissemination of Siglo de Oro studies in Brazil.

Keywords: Collective translation; Creative translation; Entremés de la Ropavejera; Quevedo y Villegas.

TradTerm, São Paulo, v.38, fevereiro/2021, p. 61-80

Número Especial - III JOTA

www.revistas.usp.br/tradterm 


\section{Introdução}

Este artigo trata de socializar a experiência de tradução coletiva do Entremés de la Ropavejera (1670) [Entremez da remendeira], escrito no século XVII pelo espanhol Francisco de Quevedo y Villegas (1580-1645), realizada pelos integrantes do Núcleo Quevedo de Estudos Literários e Traduções do Século de Ouro (UFSC). ${ }^{1}$ A edição do texto fonte para a tradução, que apresenta um extensivo aparato crítico, foi realizada por Ignacio Arellano e Celsa Carmen García Valdés, do Grupo de Investigación del Siglo de Oro (GRISO), ${ }^{2}$ e publicado em La Perinola. Revista de Investigación Quevediana, $\mathrm{n}^{\circ}$ 5, de 2001.

A título de introdução importa mencionar inicialmente algumas especificidades relacionadas tanto ao entremez como ao ato de traduzir, que serão desenvolvidas posteriormente em seção própria. Desta forma, quanto ao gênero teatral 'entremez', este é característico do Século de Ouro espanhol, período que abarca os séculos XV a XVII, e no qual houve uma intensa e inovadora produção literária. Era encenado no intervalo de peças longas com o intuito de divertir e alegrar o auditório, possuindo como aspectos essenciais a comicidade e a apresentação da vida cotidiana e popular.

O Entremés de la Ropavejera, por sua vez, possui ao todo 155 versos e está dividido metricamente, segundo os editores do texto, da seguinte forma: 111 versos são hendecassílabos e 28 heptassílabos. Destes, os últimos 15 versos são chamados de seguidilla ${ }^{3}$ cantada (com o baile ${ }^{4}$ no desfecho final). Sua história gira em torno da personagem ropavejera (remendeira), que atende na sua loja os clientes que chegam em busca de pomadas, postiços e 'peças de reposição' para remendar ou reparar em seus corpos o dano

1 A tradução do entremez, realizada pelas tradutoras Andréa Cesco [coordenadora], Mara Gonzalez Bezerra, Beatrice Távora, Cleonice M. de Brito Naedzold de Souza e Maria Eduarda da Cunha Kretzer, pesquisadoras do Núcleo Quevedo - UFSC, https: //nucleoquevedo.paginas.ufsc.br/, juntamente à tradução do Entremés de la Venta e Carta de Escarramán a la Méndez, estão publicados no livro Teatro Breve do Século de Ouro, organizado por Miguel Ángel Zamorano (UFRJ), lançado em maio de 2020 pela editora Perspectiva.

2 Grupo de Investigación del Siglo de Oro (GRISO), da Universidad de Navarra, Espanha. Disponível em: https://www.unav.edu/web/griso. Acesso 10 jan. 2021.

${ }^{3}$ Seguidilha é um tipo de canção espanhola acompanhada de dança.

${ }^{4}$ Peça dramática breve do século XVII, que era representada geralmente entre o segundo e o terceiro ato de uma comédia. Seus principais elementos eram a música, o canto e o baile.

TradTerm, São Paulo, v.38, fevereiro/2021, p. 61-80

Número Especial - III JOTA

www.revistas.usp.br/tradterm 
causado pela idade. Há um desfile de homens e mulheres que pretendem deter a passagem do tempo em sua aparência física da forma mais esdrúxula possível. Os editores do texto, Arellano e Valdés, comentam que ele está dividido em duas partes e expõem o que trata cada uma delas:

Temáticamente, el Entremés de la Ropavejera consta de dos partes: en la parte primera la ropavejera atiende de forma sucesiva a varios clientes - dos hombres y tres mujeres- que acuden a su tienda en busca de ungüentos, postizos y 'piezas de recambio' con que reparar los deterioros producidos por la edad. Este desfile de hombres y mujeres que pretenden detener en su aspecto físico el paso del tiempo es presenciado por Rastrojo, personaje que hace agudos comentarios, hasta que le toca a él, como baile viejo, ser remendado a su vez. [...] La segunda parte es el baile final en el que participan todos los bailes y bailas (QUEVEDO Y VILLEGAS 2001: 26).

No que se refere ao ato de traduzir, muitos o apontam como um ato solitário, tal como discute Alessandra Matías Querido (2011: 79). Haroldo de Campos (2010), no entanto, aponta a possibilidade da tradução coletiva como solução para textos considerados antigos ou com uma linguagem em desuso, assim como o uso da criatividade, através de uma concepção que propõe maior liberdade para criar sobre o texto fonte e menos aderida a ele. Neste sentido, o diálogo se estabelece como peça fundamental em um projeto de tradução coletiva e criativa, tal como elaborado para o texto ora problematizado, por permitir de forma concomitante uma solidez do conhecimento a partir da troca de saberes e a elaboração de um texto traduzido que não pertence a um indivíduo e sim a um grupo, envolvendo a inclusão de outros valores como a empatia e o respeito mútuo.

É através destes valores e de múltiplos saberes direcionados a um objetivo comum que os desafios do trabalho tradutório são superados, sobretudo se consideradas as complexidades envolvidas na tradução literária, uma vez que, de acordo com lúri Lotman (2001: 563 APUD AMÉRICO 2014: 24),

entre todos os textos da cultura, o mais difícil de ser traduzido (nesse caso, trata-se também da tradução de uma língua para outra) é o texto artístico, literário. Isso se deve ao fato de que, nele, mais do que nunca, predomina o fator individual, imprevisível.

TradTerm, São Paulo, v.38, fevereiro/2021, p. 61-80

Número Especial - III JOTA

www.revistas.usp.br/tradterm 
A partir desses pressupostos, as discussões entre os participantes ao longo do processo tradutório do texto quevediano permitiram a elaboração de uma metodologia de trabalho envolvendo a utilização de vários recursos, que são apresentados e discutidos a seguir. Pretende-se, assim, contribuir com a difusão de importantes e representativos textos do Século de Ouro espanhol e com os estudos tradutórios no Brasil.

\section{Entremez: contexto histórico-social, argumentos e personagens}

Margot Versteeg (2001) afirma que, no século XV, a paulatina inserção de elementos profanos no corpo do drama religioso deu lugar às farsas representadas nas praças públicas, nas feiras e carnavais. Segundo a autora (Versteeg 2001: 7), "Lo cómico y festivo es otro elemento básico, no sólo del teatro menor medieval sino de las formas teatrales breves de los siglos siguientes hasta hoy".

No entanto, no teatro castelhano, ainda segundo Versteeg (2001), a "farsa" foi logo substituída por outros como paso e entremés. E este alcança seu ponto máximo em 1615 com a publicação de Ocho Comedias y Ocho Entremeses, de Cervantes. O gênero se caracteriza, nessa primeira etapa, pelo humor carnavalesco. Na segunda etapa, o gênero sofre um forte processo de formalização e experimenta complexas transformações, no que se refere à ação, à temática ideológica e aos personagens. Nos textos de Quevedo, Hernández afirma que a verdade, a renovação, o riso coletivo do carnaval são substituídos pelo engano, pelo imobilismo e pela sátira individual dos personagens: "El resultado es una risa no sana, sino amarga, que podríamos llamar moderna" (HERNÁNDEZ 2001: 41).

Victoriano Roncero López (2012: 225) - em sua resenha do livro Teatro Completo de Quevedo y Villegas - menciona que "como muy bien destacan Arellano y García Valdés, Quevedo sobresale en el género entremesil, ya que

TradTerm, São Paulo, v.38, fevereiro/2021, p. 61-80

Número Especial - III JOTA

www.revistas.usp.br/tradterm 
los entremeses respondían 'mejor a sus gustos y habilidades de gran inventor del lenguaje y genio de la caricatura'”.

No caso do Entremés de la Ropavejera, Edgar Ceballos (2016) comenta que ele é estranho e surrealista, pois a protagonista é uma velha que compra e vende pedaços de corpos humanos: dá uma recauchutada e os vende como novos. Como em um desfile, passam pessoas necessitando dar retoques no corpo, em função do avanço do tempo, e até os músicos que, no final, pedem a ela para mudar o baile, por ser muito antiquado. Ignacio Arellano reitera que essa ideia de uma pessoa que remenda e conserta as outras mistura, de maneira assombrosa, o riso e o horror (in JIMÉNEZ, CAÑAL, MARCELLO 2017: 130).

Já Asensio (1971: 238), vai se referir a esse texto como uma reseña de figuras, expressão que parece estar relacionada à revista ou inspeção (remetendo a soldados, tropa) que se faz das personagens, com suas representações. Ele ressalta que Quevedo exaltou a revista de tipos estrambólicos vagamente unificados por um rótulo ou defeito, fornecendo maneiras de observar as fraquezas humanas. Mais adiante o autor ainda comenta (1971: 244) que a ropavejera anuncia uma mercadoria estranha, e no entremez acontece um desfile de fantasmas da corte que se esforçam por alterar o avanço (da idade), causado pelo tempo e pela natureza. Arellano também menciona as figuras de Quevedo, quando se refere ao vestuário e à estética ou, um pouco mais adiante, ao aclarar sua definição:

En los ejemplos más interesantes los vestidos ridículos, en marcada unidad con otras dimensiones de la apariencia corporal y gesto, definen las "figuras", modelos al que obedecen todos los personajes de los entremeses quevedianos.

El término "figura" designaba en la literatura jocosa del Siglo de Oro toda una gama de deformidades corporales y extravagancias morales o intelectuales que provocaban la risa o el desprecio (IN JIMÉNEZ, CAÑAL, MARCELLO 2017: 130-132).

Por outro lado, Nortan Palacio Ortiz (in JimÉnez, CAÑAL, MARCELlo 2017: 139) diz que apesar desse entremez parecer de figuras, ele é considerado grotesco, já que a ropavejera não vende roupa velha e sim retalhos de seres humanos. Hernández (2001: 49) pontua que as características essenciais do grotesco carnavalesco, como o exagero e a deformidade, frequentemente

TradTerm, São Paulo, v.38, fevereiro/2021, p. 61-80

Número Especial - III JOTA www.revistas.usp.br/tradterm 
unidos, são bastante explorados por Quevedo, de maneira desvirtuada em função do componente satírico que comportam. E assinala ainda que Quevedo chama [o espectador e o leitor] para uma reflexão ácida e implacável quanto aos próprios defeitos. "De ahí que antes de 'reírse del otro' se imponga una especie de introspección, un 'pararse a pensar'” (2001: 50).

Quanto aos personagens masculinos que nesse entremez desfilam, temos: Rastrojo [Restolho], Don Crisóstomo [Dom Crisóstomo], Ortega [Ortega] e os Músicos [Músicos]. Restolho é o personagem que está presente do começo ao fim do entremez e acompanha de perto, de forma bastante interessada, o comércio realizado pela Remendeira; os dois dialogam sobre as figuras bizarras e estapafúrdias que por ali passam requisitando os seus serviços. Ele, que faz comentários e, inclusive, dá conselhos e descreve algumas descaradas que por ali passam, é o "principal interlocutor de la protagonista, y como tal la acompaña caricaturescamente durante todo el entremés" (MAESTRO 2008: 91). Dom Crisóstomo, que é zambro, está à procura de pernas de reposição coloridas. Ortega, que é eunuco, busca uma barba preta, vasta e espessa, para ter cara de homem. Ou seja, há um "mundo deforme basado en la exageración, a modo de caricatura" (CAUZ 1966: 2169). E por fim temos os Músicos - incluindo Restolho -, que também querem que o seu baile seja restaurado: "nuestro baile del Rastro está tan viejo, I que no le queda ya sino el pellejo; / queremos, si es posible, remendalle / con los bailes pasados" (QUEVEDO Y VILLEGAS 2001: 35). Assim, à exceção de Restolho e dos músicos, que possuem um papel diferente no entremez, sobram Dom Crisóstomo e Ortega, os quais apresentam deformidades físicas. Jesús Maestro (2008: 92) afirma que o grotesco "viene dado por la yuxtaposición entre lo humano, como cuerpo físico deteriorado o estropeado por la enfermedad y la vejez, y lo artificial, como 'arreglo' o 'apaño' incompatible con una realidad humana cuya verdadera causa de deterioro se oculta o falsifica".

0 perfil das personagens femininas desse entremez - Ropavejera [Remendeira], Doña Sancha [Dona Sancha], Godínez [Godinez] e Doña Ana [Dona Ana] - também não escapa a certos estereótipos. Segundo López (1997: 124), Huerta Calvo escreve que a diferença entre a mulher do entremez

TradTerm, São Paulo, v.38, fevereiro/2021, p. 61-80

Número Especial - III JOTA

www.revistas.usp.br/tradterm 
renascentista e a do entremez barroco está no fato de a primeira ser movida por impulsos eróticos e a segunda por valores materiais.

A Remendeira - personagem presente do início ao fim - cujo ofício é mascatear, comercializa, de forma completamente esdrúxula e metafórica, retalhos humanos: pernas, braços, barbas, cabelos, pele, dente, e o que for necessário para atender a vontade dos seus clientes, que querem aparentar juventude. Dessa forma, Dona Sancha deseja dentes postiços para a boca que já não os tem; Godinez deseja voltar a ser uma mocinha; Dona Ana, que afirma ter 22 anos, julga estar velha porque, por inveja, colocaram "olho gordo", pois segundo a crença popular, pode causar malefícios ou tem o intuito ainda de prejudicar outra pessoa. Ou seja, todas as três são velhas querendo aparentar juventude. E para todos esses problemas a remendeira oferece remédio e tem sempre uma solução, mesmo que isso signifique reposição com peças de segunda mão. Maestro (2008: 92) comenta que Quevedo "subraya la hipocresía social, el embuste y la falacia, que se manifiestan ahora a través del aspecto físico de los prototipos sociales que sirven de combustible habitual a la sátira quevedesca (dueñas, viejas, sastres, calvos, desdentados, etc.)".

\section{Tradução coletiva: a metodologia}

Atualmente, muitas das traduções literárias realizadas no âmbito das universidades estão atreladas a projetos e já não acontecem mais de forma solitária, mas em grupo, de forma coletiva. E aqui nos referimos a um grupo ${ }^{5}$ que se reúne assiduamente, mas não tem a pressão do tempo; texto e/ou livro são publicados só quando estiverem de fato prontos. A tradução do Entremés de la Ropavejera - cuja edição crítica, conforme já mencionado anteriormente, oferece riquíssimas notas de rodapé, não só com relação a questões históricas, mas também no que se refere ao léxico daquela época se deu dessa forma, coletivamente, com muito estudo, reflexão e profícuas discussões, porque, afinal, o texto fonte envolve não só uma cultura e uma

\footnotetext{
${ }^{5}$ Duas são doutoras, duas são doutorandas e uma é mestre. E todas desenvolveram ou estão desenvolvendo seus trabalhos em tradução de literatura dos Séculos de Ouro. Ou seja, há uma grande bagagem cultural envolvida no processo.
}

TradTerm, São Paulo, v.38, fevereiro/2021, p. 61-80

Número Especial - III JOTA

www.revistas.usp.br/tradterm 
língua de muitos séculos atrás, como também uma versificação própria dos entremezes. Como bem menciona Oscar Osorio (2004: 94), ler os poetas barrocos do Século de Ouro exige um enorme esforço do leitor do século XXI,

\begin{abstract}
porque entre los contextos socio-culturales e ideológicos que determinaron dicha producción y los nuestros median cinco siglos que cambian sustancialmente la recepción poética [...] las lexías, los intertextos, los mitogramas, el idioma, los lenguajes poéticos (es decir, el material con el que se construyeron estas obras) es hoy en gran parte desconocido para el lector no especializado. A todo esto hay que sumar los problemas de transmisión y atribución, las variantes textuales, etc..
\end{abstract}

Sendo assim, foi necessário pensar em uma metodologia de trabalho, que o tornasse profícuo, eficiente e ágil. É importante mencionar que o grupo se reunia toda a semana, de três a quatro horas, para trabalhar no projeto. Como se trata de um texto denso e razoavelmente curto seguimos o esquema da figura 1, inspirados na metodologia sugerida por Pollux Hernúñez (in GaRCíA/YeBRA (EDS) 2005: 356-64), da Comissão Europeia e Direção Geral de Tradução - Bruxelas:

Figura 1

\title{
A TRADUÇÃO COLETIVA
}

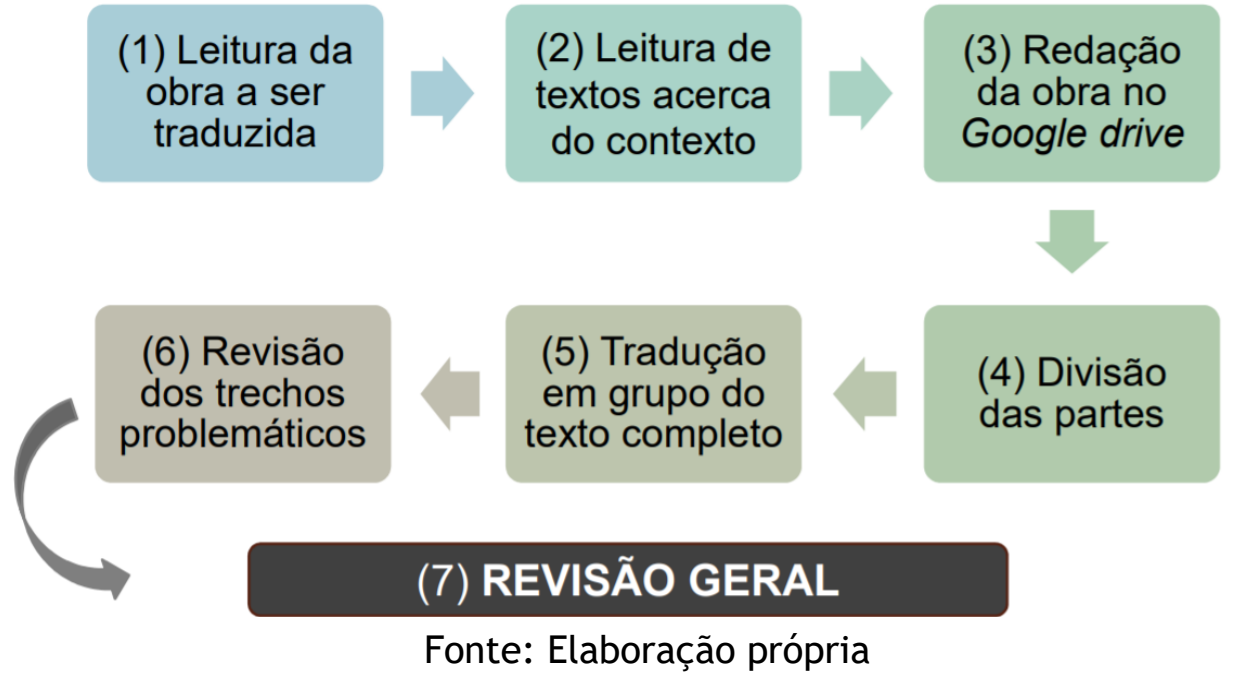

TradTerm, São Paulo, v.38, fevereiro/2021, p. 61-80

Número Especial - III JOTA www.revistas.usp.br/tradterm 
O quadro 1, como o próprio título diz, aponta para a leitura da obra a ser traduzida. No entanto, esta é precedida pela leitura dos comentários iniciais sobre o texto, oferecidos pelos editores. Logo após é realizada, concomitantemente, a leitura do texto e das notas explicativas de rodapé. Nesse momento são destacados os trechos problemáticos que oferecem obstáculos na compreensão. Tudo isso acontece em meio a comentários e debates.

0 quadro 2, uma vez que se conheça o texto e os problemas envolvendo a sua compreensão, aponta para a necessidade de se pesquisar a fundo e realizar leituras acerca do contexto. Esse é um dos momentos em que a pesquisa é realizada 'individualmente' e depois socializada e discutida pelo grupo. Destacamos a palavra 'individualmente' porque com o advento da internet, uma rede de colaboração foi formada e se encontra em total expansão (e nisso incluímos não só outros tradutores e especialistas como também sites, artigos, livros e dicionários especializados - estes, antes, só acessíveis fisicamente nas bibliotecas).

Nesse momento o texto também é disponibilizado no Google Docs, do Google Drive (quadro 3), em duas colunas: no lado esquerdo fica o texto em espanhol e no direito a tradução em português. Usamos esse serviço para Web, pois ele permite criar, editar e visualizar documentos de texto e compartilhá-los com as colegas. Todas podem trabalhar ao mesmo tempo, no mesmo arquivo, acompanhando sugestões e modificações realizadas pelas demais colegas, e com salvamento automático. Após, cada pesquisadora do grupo ficará com uma parte do texto para traduzir (quadro 4 - divisão das partes) e buscará informações que sustentem as suas escolhas. Assim, nas reuniões semanais, as traduções já realizadas serão retomadas pelo grupo para os ajustes necessários (quadro 5), tanto relacionados à questão estética (através da versificação e das rimas, por exemplo) quanto à questão de léxico. Segundo Lotman (2001: 563 apud AMÉRICO 2014: 20), “a própria possibilidade dessa tradução é determinada pelo fato de que os códigos de ambos os participantes do ato comunicativo, embora não sejam iguais, formam pluralidades intermitentes”.

TradTerm, São Paulo, v.38, fevereiro/2021, p. 61-80

Número Especial - III JOTA

www.revistas.usp.br/tradterm 
Com relação à revisão dos trechos problemáticos (quadro 6), estes dizem respeito aos trechos em que o grupo ainda não se deu por satisfeito com relação às escolhas realizadas. Não é incomum o fato de alguns trechos precisarem ser retraduzidos ou recriados pelo grupo, por um consenso, para manter questões estéticas de suma importância. Algumas vezes se perde uma rima que precisa ser retomada ou recriada logo adiante, em outras um léxico (ou um conjunto de palavras) que devia ser mantido em função da sua importância em outra parte do texto. $E$ isso nem sempre é detectado em uma primeira leitura.

Por fim temos a revisão geral (quadro 7), em que ainda podem ser detectadas algumas incongruências com relação ao texto de partida e de chegada, versos que podem ser ajustados quanto a sua versificação, e ainda rimas ou conjuntos de rimas que podem ser melhorados.

\section{Tradução criativa: engenhosidades tradutórias}

Jaime Priede (2012), em sua resenha, "Los ojos del lenguaje - quince años de trabajo en torno a la traducción entendida como creación literaria", que trata da tradução de Ars poética (Versiones de poesía moderna), editada por Andrés Sánchez Robayna (2011), comenta que:

la traducción se ofrece como un esfuerzo de recreación, de reconstituir en el texto de llegada el mismo sistema de relaciones de todo tipo presentes en el texto de origen, 'incluyendo a veces, como es natural, determinadas compensaciones allí donde no es posible reproducir tal o cual efecto'. Traducir desde esta perspectiva implica, con todo rigor, un acto de modernidad por lo que supone de exploración frente a una simple mudanza, y por lo que supone también de diálogo frente a un mero cruce de monólogos (PRIEDE 2012: 03).

Neste sentido, foram muitos os desafios enfrentados pela equipe envolvida no projeto de tradução, a começar pelo nome da protagonista, elemento chave sobre o qual se desenvolve o enredo e com desdobramentos nas questões rítmicas e métricas. As leituras preliminares, correspondentes à

TradTerm, São Paulo, v.38, fevereiro/2021, p. 61-80

Número Especial - III JOTA

www.revistas.usp.br/tradterm 
primeira e segunda fase da figura 1 acima mencionada, foram bastante elucidativas no sentido de aproximação às diversas camadas textuais permitindo o alcance semântico do intrincado estilo quevediano, das relações entre os personagens, das especificidades léxicas e da sonoridade envolvida no conjunto.

A partir desta etapa inicial evidenciaram-se ressonâncias culturais em torno do termo Ropavajera e a condensação de significados que dele emerge, aspecto mencionado por Rónai (2012: 60) que destaca os antropônimos como uma categoria de vocábulos sem sentido verdadeiro e apenas de utilidade designativa que, no entanto, é possuidora de valor conotativo dos mais fortes.

$\mathrm{O}$ acesso às ferramentas disponíveis online, a consulta a dicionários e banco de dados também aprofundou a leitura e contextualização oferecendo parâmetros para o alcance contrastivo entre os contextos de partida e de chegada, etapa preliminar à tomada de decisões. Assim, no Nuevo Tesoro Lexicográfico de la Real Academia (NTLLE) o Diccionario de Autoridades de la Real Academia (Autoridades) de 1737 foi de grande valia. Nele, a entrada "ropavejero" menciona

Figura 2: Entrada - Ropavejero

ROPAVEJEŔO. f. m. El Tendéro de ropas y veftidos vicjos. Lat. Vofium forutorius. REcor. lib.5.tit.17.1.17. Otrofi mandamos que los Ropauejéros l:o rompren por si, ni por interpóita perfona, cola alguna de almo nédas.

Fonte: NTLLE Rae/Autoridades (1737: 641)

A partir desse vendedor de roupas usadas, que de fato encontrava na atividade um meio de sobrevivência no panorama de crise do século XVII espanhol, Quevedo acrescenta outros elementos, elaborando uma figura caricaturesca no intuito de provocar o riso, conforme mencionado nas seções anteriores. A multiplicidade de sentidos emana do texto quevediano, a partir da descrição que a própria personagem enuncia de si. Nos versos 1 e 2 é questionada por Rastrojo (Restolho): “¡Válgame Dios, qué extraordinaria cosa! / ¿Qué oficio dice vuesarced que tiene?" e responde nos versos 3 e 4:

TradTerm, São Paulo, v.38, fevereiro/2021, p. 61-80

Número Especial - III JOTA

www.revistas.usp.br/tradterm 
"Muy presto se le olvida:/ yo soy ropavejera de la vida", complementando nos versos 8 a 13 que

\author{
Soy calcetera yo del mundo junto, \\ pues los cuerpos son de punto, \\ como calza de aguja: \\ cuando se sueltan en algunas barbas \\ puntos de canas, porque estén secretas, \\ les echo de fustán unas soletas \\ (QUEVEDO Y VILLEGAS 2001: 28).
}

Desta forma, se apresenta uma figura feminina com certos poderes de atuar sobre a natureza, remendando corpos que parecem ter sido construídos em teares, como vestimentas gastas pelo tempo, e que alude a práticas de fato existentes no período, como o ofício de 'remendavirgos'6 para recuperar a honra das mulheres. Esta realidade é bastante distante do leitor contemporâneo e a as possibilidades disponíveis no acervo léxico do português poderiam seguir em direção a uma solução mais literal, que ao mesmo tempo se constituiria como um neologismo, como 'roupavelha', ou centrar-se em uma solução determinada pela negociação dos elementos a serem priorizados no contexto de chegada. Após a pesquisa inicial e a discussão em grupo, quinta etapa do organograma de atividades esboçado na seção três, as opções se restringiram a quatro termos: 'cerzideira', 'costureira', 'farrapeira' e 'remendeira'.

O fator decisivo na eleição final considerou a sonoridade do termo, aspecto que tem desdobramentos no desenvolvimento do entremez como um todo, uma vez que parece haver uma predominância das aliterações entre as consoantes $\mathrm{r} / \mathrm{s}$, além de uma relativa proximidade com o termo de partida no que respeita à primeira sílaba. Não foram abandonadas, no entanto, as demais palavras, que passaram a estar presentes no corpo do texto, evitando a perda da riqueza lexical elaborada por Quevedo.

6 O trabalho das Remendavirgos ou celestinas consistia em 'devolver' a virgindade das donzelas. Era realizado na clandestinidade e aparece mencionado na La Celestina, de Fernando Rojas, publicada em 1499.

TradTerm, São Paulo, v.38, fevereiro/2021, p. 61-80

Número Especial - III JOTA

www.revistas.usp.br/tradterm 
Se por um lado a opção 'Remendeira' significou uma perda no que tange ao comércio de roupa usada e pode obscurecer alguns aspectos históricos relacionados à profissão exercida no contexto de crise da Espanha áurea, o que era compartilhado pelo espectador do período que acessava imediatamente essa carga de informações, por outro, privilegiou elementos da descrição dada pela própria personagem nos versos já mencionados, trazendo à tona um pensamento que não se perdeu ao longo do tempo, relacionado à supremacia da aparência em detrimento da realidade e às estratégias humanas de impedir o passar dos anos. Ao afirmar-se 'calcetera del mundo junto' e mencionar a 'calza de aguja' como a vestimenta comparável ao corpo, a personagem é bastante específica e novamente deixa entrever seu contexto social através de uma profissão que caía em desuso no período, de acordo com o Autoridades (1729: 61). Some-se a isso a possível alusão de Quevedo à gíria do período que designava 'calcetero' aquele que colocava as correntes nos que eram encaminhados à prisão, de forma que além de consertar o corpo, a 'ropavejera' também o manteria atado, amarrado a determinadas concepções da época que viam na beleza do corpo a beleza da alma ${ }^{7}$. Isso motivou a uma solução voltada para o contexto de chegada, que, embora não insira a estranheza da alusão à 'calza de aguja', privilegia a prática da costura e do remendo, já não tão presente no contexto brasileiro do século XXI como esteve em períodos anteriores, e permite manter uma metáfora compreensível pelo leitor/espectador da atualidade. Desta forma, o delineamento do texto final passou por várias etapas, como ilustra a imagem a seguir:

\footnotetext{
${ }^{7}$ Exemplo disto está no neoplatonismo que, segundo Josa e Lambea (2010: 182) dignificou a experiência do deleite visual do corpo feminino ao convertê-lo em reflexo da bondade divina.

TradTerm, São Paulo, v.38, fevereiro/2021, p. 61-80

Número Especial - III JOTA

www.revistas.usp.br/tradterm
} 
Figura 3: Etapas da tradução

\begin{tabular}{|c|c|c|}
\hline Texto de partida & Texto de chegada I & Texto de chegada 2 \\
\hline $\begin{array}{l}\text { Soy calcetera yo del } \\
\text { mundo junto, }\end{array}$ & $\begin{array}{l}\text { Sou remendeira do mundo } \\
\text { atado, }\end{array}$ & $\begin{array}{l}\text { Sou costureira do mundo } \\
\text { remendado, }\end{array}$ \\
\hline $\begin{array}{l}\text { pues los cuerpos humanos } \\
\text { son de punto, }\end{array}$ & $\begin{array}{l}\text { pois os corpos humanos são } \\
\text { tricotados, }\end{array}$ & $\begin{array}{l}\text { pois os corpos humanos são } \\
\text { costurados, }\end{array}$ \\
\hline como calza de aguja: & como calça de agulha: & com linha e agulha: \\
\hline $\begin{array}{l}\text { cuando se sueltan en } \\
\text { algunas barbas }\end{array}$ & $\begin{array}{l}\text { quando se soltam em alguns } \\
\text { fios }\end{array}$ & $\begin{array}{l}\text { quando se soltam alguns dos } \\
\text { fiapos }\end{array}$ \\
\hline $\begin{array}{l}\text { puntos de canas, porque } \\
\text { estén secretas, }\end{array}$ & $\begin{array}{l}\text { pontos de agulha , para } \\
\text { esconder, }\end{array}$ & $\begin{array}{l}\text { pontos cerzidos, para que } \\
\text { fiquem secretos, }\end{array}$ \\
\hline $\begin{array}{l}\text { les echo de fustán unas } \\
\text { soletas }\end{array}$ & $\begin{array}{l}\text { remendos de fustão passo a } \\
\text { coser }\end{array}$ & $\begin{array}{l}\text { são meus remendos } \\
\text { prediletos }\end{array}$ \\
\hline
\end{tabular}

Fonte: Elaboração própria

Observa-se na etapa que antecedeu a versão final do texto a diferença entre as soluções encontradas e a adoção de estratégias criativas em torno dos vários níveis que compõem a informação estética, sejam eles semânticos, sintáticos ou fônicos. Assim, através do trabalho do grupo, recriou-se o texto em alguns pontos, onde a rima e o jogo entre as palavras perderiam força, explorando a criatividade, tal como propõe Campos ao afirmar que:

A tradução de textos criativos será sempre recriação, ou criação paralela, autônoma, porém recíproca. Quanto mais inçado de dificuldades esse texto, mais recriável, mais sedutor enquanto possibilidade aberta de recriação. Numa tradução dessa natureza, não se traduz apenas o significado, traduz-se o próprio signo (CAMPOS 2010: 35).

O trabalho final de revisão, etapa ilustrada no quadro 6 da seção 3, foi minucioso em relação às escolhas realizadas até se chegar a um consenso, e 
suscitou discussões bastante produtivas a partir da experiência de cada uma das componentes do grupo que, conforme afirmado anteriormente, desenvolvem pesquisas sobre a obra quevediana.

A proposta de tradução, através da metodologia descrita, também se mostrou bastante enriquecedora por consolidar na prática uma vivência em torno do respeito envolvido na troca de ideias, aspecto que merece ser destacado como componente da formação integral do ser.

\section{Considerações finais}

O texto integral, Entremez da Remendeira, conforme já comentado em nota de rodapé, está publicado na obra Teatro Breve do Século de Ouro (2020). ${ }^{8}$ Nesta obra, que traz a tradução inédita de diversos textos dramáticos literários - preenchendo uma imensa lacuna nessa área - o entremez ganha destaque.

Assim, através deste artigo procuramos socializar a experiência de tradução coletiva de um texto bastante complexo, justificada pela relevância do autor e pela carência não só de obras do período áureo no cenário nacional, como também de peças curtas de teatro para serem trabalhadas nos cursos de Artes Cênicas. Ao longo do período em que o processo tradutório foi desenvolvido a metodologia aqui apresentada se consolidou, razão pela qual entendemos ser pertinente compartilhá-la. Esta experiência se mostrou muito produtiva, desmitificando de certa forma a representação do tradutor como trabalhador solitário e explicitando a pertinência do uso de diversas ferramentas como facilitadoras do acesso a informações que sedimentam a tomada de decisões. Ademais, quando vários pesquisadores, que compartilham conhecimento acerca de uma obra ou de um autor, se associam em um trabalho que exige uma boa dose de criatividade na tradução, a chance de se pensar em engenhosas e inventivas soluções é bem maior. E no que se refere ao grau de criatividade ou de invenção por parte do tradutor, em textos tão distantes culturalmente e que guardam marcas que precisam

8 Editora Perspectiva: https://editoraperspectiva.com.br/produtos/teatro-breve-do-seculode-ouro/. Acesso 10 jan. 2021

TradTerm, São Paulo, v.38, fevereiro/2021, p. 61-80

Número Especial - III JOTA

www.revistas.usp.br/tradterm 
ser decifradas para não perderem seu valor estético, partilhamos do aqui exposto por Jandová, após citar Jan Mukařovský, teórico e crítico literário checo:

Assim, a tarefa do tradutor literário consistiria em desentranhar os elementos portadores da estrutura da obra, aqueles que permitirão que a obra original continue funcionando como 'objeto estético' em um novo contexto cultural, e buscar sua equivalência no processo da tradução. Nesse sentido, ser fiel ao original requer realmente um considerável grau de criatividade ou de invenção por parte do tradutor (JANDOVÁ 2017: 297, tradução nossa).

Acreditamos, portanto, que o trabalho de tradução coletiva é capaz de condensar múltiplos saberes e, ainda que sejam vários os desafios envolvidos nesta proposta, a tarefa se torna bastante enriquecedora e gratificante, possibilitando que os efeitos do texto enquanto "objeto estético", como aponta Jandová (2017), possam ecoar em um tempo e em uma cultura diferentes daquela em que foi produzida.

TradTerm, São Paulo, v.38, fevereiro/2021, p. 61-80

Número Especial - III JOTA www.revistas.usp.br/tradterm 


\section{Referências}

AMÉRICO, E. V. O conceito de tradução na obra de lúri Lotman: entre intraduzibilidade e liberdade. TradTerm, São Paulo, v. 24, 2014. pp. 17-33. Disponível em:

http://www.revistas.usp.br/tradterm/article/view/96128. Acesso 10 jan. 2021.

ASENSIO, E. El itinerario del entremés, $2^{\mathrm{a}}$ ed., Madrid: Editorial Gredos S.A., 1971.

CAmpos, H. Metalinguagem e outras metas: ensaios de teoria e crítica literária. São Paulo: Perspectiva, 2010.

CaUz, F. A. Un Quevedo poco conocido. Boletín Cultural y Bibliográfico de la Biblioteca Luis Angel Arango del Banco de la República, Colombia, n.11, 1966, pp. 2166-2169. Disponível em:

https://publicaciones.banrepcultural.org/index.php/boletin_cultural/ article/view/4543/4774. Acesso em: 10 jan. 2021.

Ceballos, E. Cómo escribir teatro. Historia y reglas de dramaturgia. Escenología ediciones, 2016.

Diccionario de autoridades de la REAL ACADEMIA EsPañola. Disponível em: http://www.rae.es/recursos/diccionarios/diccionarios-anteriores1726-1996/diccionario-de-autoridades Acesso 10 jan. 2021.

GarcíA, C. G.; Yebra, V. G. (eds.). Manual de documentación para la traducción literaria. Madrid: Arco/Libros, S.L., 2005.

HeRnÁNDEZ, J. L. A. Transformaciones carnavalescas en los Entremeses de Quevedo, in Foro Hispánico, 19, En torno al teatro breve. Amsterdam - Atlanta, Rodopi, 2001. pp. 41-53. Disponível em:

https://brill.com/view/title/29723. Acesso em: 10 jan. 2021.

JANDOVÁ, J. La creatividad del traductor literario y la ilusión de traducción. Literatura: teoría, historia, crítica. Colombia, v. 19, n. 2, pp. 291314, 2017. Disponível em:

https: / / revistas.unal.edu.co/index.php/lthc/issue/view/4660/showTo c. Acesso 10 jan. 2021.

Jiménez, F. B. P.; Cañal, R. G.; MARCello, E. E. (ed.). El entremés y sus intérpretes: XXXVIII Jornadas de teatro clásico, Almagro, 2015. Cuenca [España]: Ediciones de la Universidad de Castilla-La Mancha, 2017.

JosA, D.; LAMBEA, M. Señas de una belleza superior o las representaciones del cuerpo en el tono humano barroco, in Desvelando el cuerpo. Perspectivas desde las ciencias sociales y humanas. MARTí, J.; AIXELÀ,

TradTerm, São Paulo, v.38, fevereiro/2021, p. 61-80

Número Especial - III JOTA

www.revistas.usp.br/tradterm 
Y. (coords.), Barcelona: Digital CSIC, 2010, pp. 181-200. Disponível em: http://hdl.handle.net/10261/22355. Acesso em: 10 jan. 2021.

LóPEZ, V. R. "QUEVEDO, Francisco de. Teatro completo", Criticón, 114. pp. 225-228. Disponível em:

https://journals.openedition.org/criticon/1456. Acesso em: 10 jan. 2021.

MAESTRO, J. G. Las formas de lo cómico en los entremeses de Quevedo, in La perinola. Revista de Investigación Quevediana, n. 12, 2008. pp. 79105. Disponível em: https://revistas.unav.edu/index.php/laperinola/article/view/27941. Acesso em: 10 jan. 2021.

MARTínez-López, M. J. M. El entremés. Radiografía de un género. Anejos de Criticón, 9, Toulouse, Presses Universitaires Du Mirail, 1997.

OsoRIO, O. La Jácara del Escarramán, de Quevedo. Poligramas, n. 21, 2004, pp.93-119. Disponível em: http://hdl.handle.net/10893/2882. Acesso em: 10 jan. 2021.

PRIEDE, J. Los ojos del lenguaje - quince años de trabajo en torno a la traducción entendida como creación literaria, in Boletín del Taller de Traducción Literaria de la Universidad de La Laguna, febrero de 2012.

QUERIDO, A. M. Investigando Jerônimos: A representação do tradutor como personagem em narrativas contemporâneas. Universidade de Brasília, 2011. Tese de doutorado em Literatura. Disponível em: https://repositorio.unb.br/bitstream/10482/11103/1/2011_Alessandr aMatiasQuerido.pdf. Acesso em: 10 jan. 2021.

QUeVEDO Y VILLEGAS, F. El Entremés de la Ropavejera, Edição crítica de Ignacio Arellano e Celsa Carmen García Valdés (GRISO, Universidad de Navarra), in La Perinola. Revista de Investigación Quevediana, 5, 2001. pp. 25-38. Disponível em:

https://revistas.unav.edu/index.php/la-perinola/article/view/28129. Acesso em: 10 jan. 2021.

RónAl, P. A tradução vivida. Rio de Janeiro: José Olympio, 2012.

VeRSTEEG, M. (coord.). Introducción: una placentera exploración por el variopinto panorama del teatro breve, in Foro Hispánico, 19, En torno al teatro breve. Amsterdam - Atlanta, Rodopi, 2001. pp. 7-10. Disponível em https://brill.com/view/title/29723. Acesso em: 10 jan. 2021.

Zamorano, M. Á. (org.). Teatro Breve do Século de Ouro. $1^{\text {a }}$ ed. São Paulo: Perspectiva, Brasília, DF: CNPq, 2020.

TradTerm, São Paulo, v.38, fevereiro/2021, p. 61-80

Número Especial - III JOTA

www.revistas.usp.br/tradterm 
Recebido em: 18/02/2020

Aceito em: 22/09/2020

Publicado em fevereiro de 2021

TradTerm, São Paulo, v.38, fevereiro/2021, p. 61-80

Número Especial - III JOTA

www.revistas.usp.br/tradterm 